\title{
Determination of the groundwater recharge in the Blagoevgrad valley Neogene sediments
}

\author{
Marin Ivanov ${ }^{I}$, Evelina Damyanova ${ }^{l}$, Gergana Droumeva ${ }^{1}$
}

'National Institut of Meteorology and Hydrology, Sofia, Bulgaria; e-mail: marin.ivanov@meteo.bg

\section{Определяне на естественото подхранване на подземните води в неогенските седименти на Благоевградската котловина}

\author{
Марин Иванов, Евелина Дамянова, Гергана Друмева
}

Ivanov, M., E. Damyanova, G. Droumeva. 2020. Determination of the groundwater recharge in the Blagoevgrad valley Neogene sediments. Engineering Geology and Hydrogeology, 34, 19-28.

\begin{abstract}
A comprehensive approach to determine the natural groundwater recharge in the Blagoevgrad valley Neogene sediments is presented. It involves the application of various methods such as the balance method, hydrodynamic modeling in GIS, the FeFlow numerical model, the Döll et al. empirical method. The obtained results show good similarity between different methods, including the long-term groundwater recharge for the study area calculated by rainfall infiltration. Therefore, the complex approach used gives an accurate estimate of the groundwater recharge in the Blagoevgrad valley associated with Neogene sediments. It can be successfully applied to determine the natural groundwater resources for other similar groundwater bodies. In this way, the groundwater resource assessments, management and conservation in Bulgaria can be significantly improved.
\end{abstract}

Keywords: groundwater recharge, balance method, GIS, geostatistical model, numerical model FeFlow, Döll et al. method, Blagoevgrad valley.

Резюме. Представен е комплексен подход за определяне на естественото подхранване на подземните води в неогенските седименти на Благоевградската котловина. Той включва прилагане на различни методи като балансов метод, хидродинамично моделиране в ГИС среда, числен модел FeFlow, емпиричен метод на метод на Döll и др. Получените резултати за подхранването показват много добра сходимост, включително сравнени със стойността на многогодишното подхранване на изследвания район, изчислено по инфилтрацията на валежите. Следователно, използваният комплексен подход дава достатъчно точна представа за реалната стойност на подхранването на подземните води в неогенските седименти на Благоевградската котловина. Той може да бъде успешно прилаган за определяне на естествените ресурси на подземните води и за други подобни подземни водни тела. По този начин в значителна степен биха могли да се подобрят ресурсните оценки, управлението и опазването на подземните води в България.

Ключови думи: подхранване на подземните води, балансов метод, ГИС, геостатистически модел, числен модел FeFlow, метод на Döll et al., Благоевградска котловина. 


\section{Въведение}

Прецизното определяне на естественото подхранване на подземните води е от особена важност за постигане на техния добър количествен статус в съответствие с Рамковата директива за водите (РДВ, 2000/60/EC $\left.{ }^{1}\right)$ и съставените съобразно нея Плановете за управление на речните басейни (ПУРБ, 2016-20212). Тяхна основна цел е предотвратяване на влошаването, защита и подобряване на състоянието на водите. Съгласно Закона за водите (ЗВ, изм. и доп. 2010 г.), Националният институт по метеорология и хидрология (HИМХ) извършва мониторинг на подземните води, подготвя ежегодна оперативна оценка на естествените ресурси на подземните води и извършва количествена оценка за подземните водни тела. За изпълнение на част от тези дейности, Министерството на околната среда и водите (МОСВ) одобрява „Методика за определяне на ресурсите на подземните водни тела с отчитане на изменението на климатичните фактори и необходимия за изпълнението ѝ мониторинг на количеството на водите“" (Бендерев и др., $2012^{3}$ ). Предложени са сравнително достьпни и лесни за използване методи за оценка на ресурсите на ПВТ, които се базират на прилагането на електронни таблици в MS Excel среда. Опитът показа, че за множество подземни водни тела, включително и такива, които са в риск по отношение на количественото си състояние, е невъзможно да се определи естественото им подхранване по приетата Методика и с наличната база данни. Това налага използването на комплексен подход за оценка на естествените ресурси на подземните води, включващ посложните методи като хидрогеоложкото моделиране, геостатистически модел и др. Пример за такъв подход е представен в настоящата статия.

\section{Предмет на изследване}

Предмет на изследване са подземните води в неогенските седименти на Благоевградската котловина, за които е определено естественото подхранване чрез прилагане на различни методи за оценка. Котловината е образувана през Плиоцена в резултат на потьване по разломните линии. В централната ѝ част преобладават алувиални и алувиално-пролувиални наноси, а в периферията ѝ - плиоценски и делувиални наслаги. Голяма част от котловината е заета от разлетия наносен конус на река Благоевградска Бистрица. Климатът в района е преходно-континентален със средиземноморско влияние. Средната годишна температура на въздуха $12,6^{\circ} \mathrm{C}$, а средната годишна валежна сума - $517 \mathrm{~mm}$ по данни от метео станция Благоевград. Котловината се отводнява от река Струма и долните течения на притоците ѝ Благоевградска Бистрица (ляв) и Логодашка река (десен), (Big encyclopedia Bulgaria, 2011).

Разгледано е подземно водно тяло (ПВТ) с код BG4G000000N014 и наименование „Порови води в Неоген - Благоевград”. Водният колектор е поров, представен от слабоспоени чакъли, пясъци и глини. Изследваното подземно водно тяло е от напорен тип и е слабо водообилно (ПУРБ, 2016-2021). Общата площ на ПВТ е $240,39 \mathrm{~km}^{2}$.

\section{Прилагане на методи по одобрената от МОСВ Методика за ПВТ „Порови води в Неоген - Благоевград"}

За определяне на естественото подхранване на изследваното ПВТ по приетата Методика са подходящи два метода - метода нива в кладенци и балансовия метод.

${ }^{1}$ Рамкова директива за водите. 2000. РДВ, 2000/60/ЕС.

${ }^{2}$ План за управление на речните басейни, Западнобеломорски район, ПУРБ. 2016-2021.

${ }^{3}$ Бендерев и др. 2012. Методика за определяне на ресурсите на подземните водни тела с отчитане на изменението на климатичните фактори и необходимия за изпълнението ѝ мониторинг на количеството на водите. МОСВ. 90 с. 
НИМХ разполага само с един пункт № $561 \mathrm{T1}$ в разглежданото тяло с липсващи литоложко описание и параметри на пласта. Пунктьт се намира на територията на гр. Благоевград, кв. Изгрев и е предаден за измерване на НИМХ от Басейнова дирекция (БД) „Западнобеломорски район“ през 2013 г. От БД в Благоевград са предоставени режимни данни от 2008 до 2013 г., като информацията до 2013 г. е с честота 4 пъти годишно и представлява къса и непълна редица от данни. От хидрографа на пункт № 561T1 към този момент не може да се установи дали колебанията на нивото на подземните води са в резултат на естествени или изкуствени причини. Подобни данни поставят под съмнение пригодността на данни от наблюдателния пункт за извършване на ресурсни оценки.

За прилагане на балансовия метод са използвани данни от синоптични станции Дупница и Благоевград за 2017 г. Данни за слънчева радиация са взети от Методиката. И двете станции попадат в границите на ПВТ „Порови води в Неоген - Благоевград” и имат сходни надморски височини, съизмерими с тази на ПВТ. Получените резултати са показани в таблица 1.

Таблица 1. Естествено подхранване на ПВТ „Порови води в Неоген - Благоевград”, определено по балансов метод за 2017 г.

Table 1. Natural recharge of groundwater body „Porous waters in Neogene - Blagoevgrad“ determined by balance method for 2017

\begin{tabular}{|l|l|l|l|}
\hline Станция & Подхранване, $1 / \mathrm{s}$ & Модул, L/s/km² & Подхранване, $\mathrm{mm} / \mathrm{a}$ \\
\hline Благоевград & 74,03 & 0,308 & 9,7 \\
\hline Дупница & 140,1 & 0,583 & 18,4 \\
\hline Средно & 107,06 & 0,445 & 14,05 \\
\hline
\end{tabular}

За естественото подхранване на ПВТ „Порови води в Неоген - Благоевград” средно от двете станции за 2017 г. се получава 14,05 mm/a.

\section{Използване на хидродинамичен метод в ГИС среда за оценка на естественото подхранване на ПВТ „Порови води в Неоген - Благоевград"}

За определяне естествените ресурси на разглежданото ПВТ е използван хидродинамичен метод, който е приложен по два различни начина, представени по-долу. Изборьт на този метод е направен поради липса на достатъчен брой мониторингови пунктове.

Извършени бяха полеви обходи за измерване на абсолютните коти на кладенци и водни нива от терена за 23 броя кладенци в периода 11-15 юни 2018 г. На 5 места бяха измерени и котите, и наклона на избрани потоци и реки от разглежданата област. Допълнително бе използвана информация за нивото на подземните води в единствения пункт от мрежата на НИМХ, представящ подземните води в Неогена на Благоевград, както и 3 кладенеца с информация, публикувана от БД „Западнобеломорски район“, като нивата за пунктовете от Басейновата дирекция са за неизвестен период. Всички използвани кладенци са показани на фигура 1.

\section{1) Хидродинамичен геостатистически модел}

Първият използван подход за направа на карта с хидроизохипси е в ГИС среда чрез прилагане на интерполационния инструмент „Topo to Raster“" (Kresic, Mikszewski, 2012; Cushman, Tartakovsky, 2016). Това е специално създаден инструмент в ГИС, имащ за цел със сравнително малко информация да се създаде цифров модел на филтрационното поле, като специално внимание се обръща на хидроложките му особености. Методът използва итеративна процедура за интерполация, работеща 
по метода на крайните разлики и е оптимизиран да достига добра изчислителна ефективност, съответстваща на локалните интерполационни модели като IDW inverse distance weighted, а в същото време запазва непрекъснатостта на полето, което е характерно за глобалните методи като Kriging (Childs, 2004; Garnero, Godone, 2013). За входни данни се използват векторни точки, линии и полигони. Инструментът дава възможност да се задават различни ограничения или изисквания, като например: задаване на реките, като векторни линии; задаване граници, прекъсващи средата, като разломи, брегове на водни басейни и др.; задаване на езера с константна надморска височина и др.

Методът е приложен при следните допускания:

- Съществуващите временни потоци и реки са естествени граници на дрениране на подземните води.

- Нивата на подземните води следват релефа, като го изглаждат.

- Използваният модел има за цел да направи регионална оценка и е възможно да не отразява локалните особености и частни случаи.

Важна особеност за осигуряване прецизността на метода е задаване на коректни данни. За тази цел е необходимо да се използват достатъчен брой точки, отразяващи наклоните на речната мрежа в нейните различни участыци. Тези точки могат да се вземат от топографска основа или цифров модел на терена. В този случай е използван цифров модел на терена, който предварително е обработен в ГИС-среда посредством инструмента „HEC-GeoHMS”, с цел коригиране на съществуващият грид за коректно представяне на речната мрежа в района на изследване.

Използваните данни са:

- Надморски височини на нивата на подземните води от 26 бр. кладенци векторни точки;

- Речна мрежа - векторен формат - линии;

- Точки с надморски височини на речната мрежа, като техните коти са взети от коригирания цифров височинен модел на терена с размер на клетката 50*50 m;

- Граница на подземното водно тяло - векторен полигон.

След като се направи полето с разпределение на напорите на подземния поток, от него може да се извадят две основни съставляващи, а именно: средния напорен градиент I за изучаваната област и средната дължина на хидроизохипсите. Третата необходима съставляваща е проводимостта на пластта, която не винаги е известна за цялата площ.

Съгласно закона на Дарси, разходът на потока през дадено сечение може да се изчисли по формулата

$$
Q=T . I . L
$$

където: $Q$ - разхода на потока, $\mathrm{m}^{3} / \mathrm{d} ; T$ - проводимост на пластта, $\mathrm{m}^{2} / \mathrm{d} ; I$ напорен градиент на подземния поток, безразмерна величина; $L$ - дължина на сечението, за което се определя разхода на потока, m (Galabov, Stoyanov, 2005).

Получените резултати са илюстрирани на фигура 2. За пресмятане на разхода на подземния отток са използвани само хидроизохипсите (показани в син цвят), които попадат в зони, за които има измерени водни нива на подземните води. Останалите хидроизохипси, показани с розов цвят, не са използвани за оценка, защото представляват екстраполации и не взимат под внимание нивата на подземните води или попадат в кватернера извън неогенските седименти. Наличните данни за проводимостта на пласта са показани на фигура 3.

Отново с помощта на ГИС е направен грид с разпределение на наклоните в различните части на изучаваната област, показан на фигура 4, от който се получава среден напорен градиент 3,63 \% или 0,0363 .

Средната дължина на всички хидроизохипси е $10000 \mathrm{~m}$. 
Проводимостта, определена по данни от водочерпене в един сондаж, е 5 $\mathrm{m}^{2} / \mathrm{d}$. При достатъчен брой данни за проводимостта на пласта, отново с помощта на геостатистическите методи, е възможно да се определи с по-голяма точност разход на потока за изучавания район.
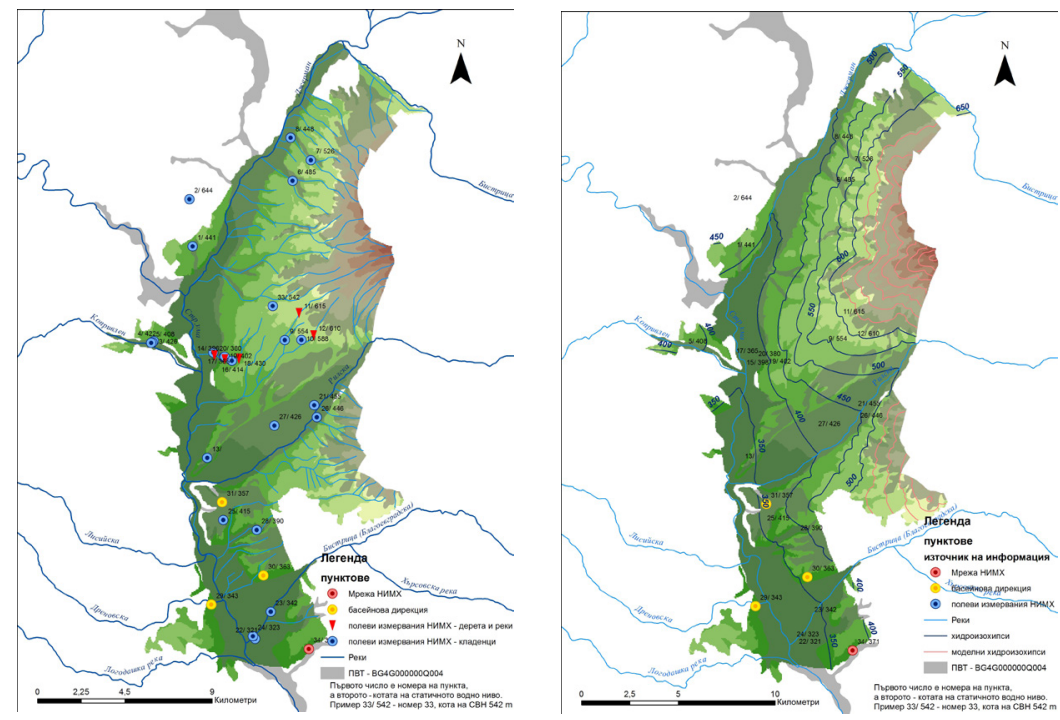

Фиг. 1. Местоположение на използваните пунктове в ПВТ „Порови води в Неоген - Благоевград” Fig.1. Location of the water measurement points in groundwater body "Porous waters in Neogene - Blagoevgrad"

Фиг. 2. Хидродинамична карта на ПВТ „Порови води в Неоген - Благоевград”, получена в ГИС

Fig. 2. Hydrodynamic map of groundwater body "Porous waters in Neogene - Blagoevgrad" compiled with GIS
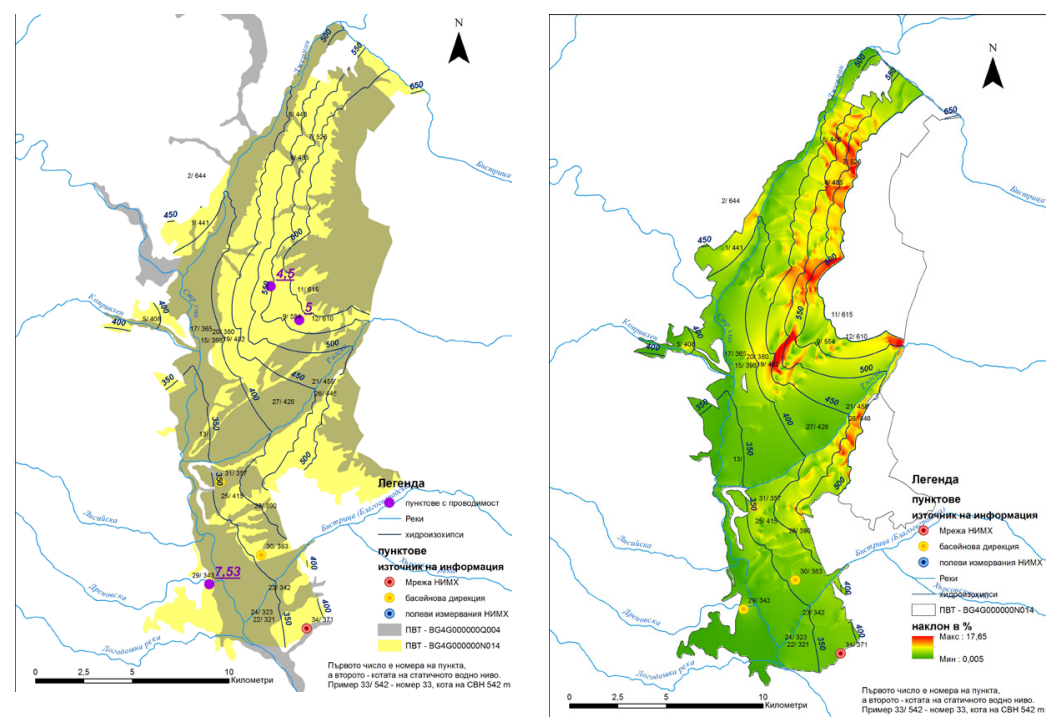

Фиг. 3. Хидродинамична карта, използвана за оценка на филтрационния поток на ПВТ „Порови води в Неоген - Благоевград"

Fig. 3. Hydrodynamics map used to estimate groundwater flow within groundwater body "Porous waters in Neogene - Blagoevgrad"

Фиг. 4. Напорен градиент на филтрационното поле на ПВТ „Порови води в Неоген - Благоевград” Fig. 4. Hydraulic gradient in the aquifer presented of groundwater body "Porous waters in Neogene - Blagoevgrad" 
Съгласно закона на Дарси (1), разходът на потока през дадено сечение е:

$Q=$ T.I.L $=5.0,0363.10000=1815 \mathrm{~m}^{3} / \mathrm{d}=21 \mathrm{~L} / \mathrm{s}$

$\mathrm{T}=5 \mathrm{~m}^{2} / \mathrm{d}$

Изчисленото водно количество се отнася за площ от $185,05 \mathrm{~km}^{2}$ и представлява около $77 \%$ от общата площ на тялото.

Общата площ на ПВТ е $240,39 \mathrm{~km}^{2}$, съответно филтрационният разход за нея е $27,3 \mathrm{~L} / \mathrm{s}$. Модулът на подземния отток е $0,113 \mathrm{~L} / \mathrm{s} / \mathrm{km}^{2}$, което отговаря на величината на подхранване на подземните води $3,58 \mathrm{~mm} / \mathrm{a}$.

\section{2) Хидродинамичен числен модел}

За оценка подхранването на разглежданото ПВТ е използван числен модел, обхващащ голяма част от него. Численият модел е направен със софтуера FeFlow, използващ метода на крайните елементи. Моделната мрежа има неправилна форма изградена от елементи с триъгълна форма, върховете на които представляват изчислителните възли или нодове. Състои се от 6332 елемента и 3324 изчислителни възела.

Моделът е зададен е като двумерен стабилизиран режим на филтрация (фигура 5). На запад се ограничава от р. Струма, а на север от р. Бистрица, които са зададени като условия от I род - граница с постоянен напор. Източната граница няма зададено условие, както и южната. В самата моделна област всички граници (реки) са зададени като условия от III род. Численият модел е калибриран със софтуера PEST, който с помощта на статистически подходи решава т.н. обратна задача. За калибриране са използвани напорите на подземните води в съществуващите водовземни съоръжения, както и стойностите за проводимостта в двата кладенеца разположени в централната част на ПВТ. Калибрирането се състои в търсене решение на задачата, чрез използване на произволни стойности за проводимост и подхранване до достигане на съответствие между измерените и моделирани напори.

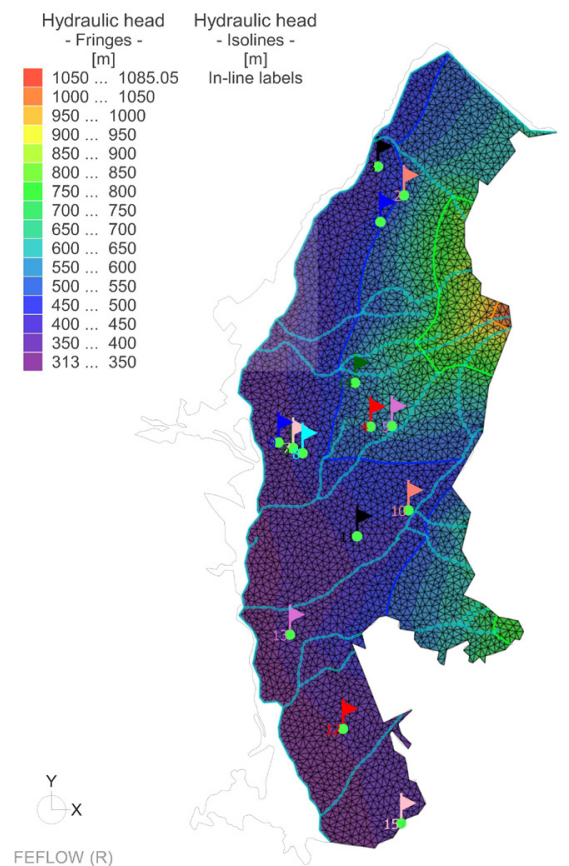

Фиг. 5. Числен модел FeFlow на ПВТ „Порови води в Неоген - Благоевград"

Fig. 5. Numerical model FeFlow of groundwater body "Porous waters in Neogene - Blagoevgrad" 
Калибрирането на модела достигна до следните резултати, представени в таблица 2.

Таблица 2. Резултати от калибрирането на хидродинамичния числен модел на ПВТ „Порови води в Неоген - Благоевград”

Table 2. Hydrodynamic numerical model calibration results for groundwater body "Porous waters in Neogene - Blagoevgrad"

\begin{tabular}{|c|c|c|c|}
\hline Номер & Измерени нива, $\mathrm{m}$ & Моделирани нива, $\mathrm{m}$ & Грешка, $\mathrm{m}$ \\
\hline hеа-1 & 485,38 & 485,315 & $6,0 \mathrm{E}-02$ \\
\hline hea-2 & 526,19 & 526,155 & $3,3 \mathrm{E}-02$ \\
\hline hea-3 & 448,49 & 448,504 & $-1,8 \mathrm{E}-02$ \\
\hline hea-4 & 554,395 & 557,019 & $-2,6 \mathrm{E}+00$ \\
\hline hea-5 & 588,109 & 581,795 & $6,3 \mathrm{E}+00$ \\
\hline hea-6 & 396,383 & 394,403 & $2,0 \mathrm{E}+00$ \\
\hline hea-7 & 398,231 & 398,369 & $-1,4 \mathrm{E}-01$ \\
\hline hea-8 & 414,493 & 415,818 & $-1,3 \mathrm{E}+00$ \\
\hline hea-9 & 365,138 & 367,626 & $-2,5 \mathrm{E}+00$ \\
\hline hea-10 & 454,627 & 454,189 & $4,4 \mathrm{E}-01$ \\
\hline hea-11 & 425,935 & 425,985 & $-5,0 \mathrm{E}-02$ \\
\hline hea-12 & 362,89 & 362,714 & $1,8 \mathrm{E}-01$ \\
\hline hea-13 & 357 & 362,01 & $-5,0 \mathrm{E}+00$ \\
\hline hea-14 & 542 & 541,487 & $5,1 \mathrm{E}-01$ \\
\hline hea-15 & 371 & 370,803 & $2,0 \mathrm{E}-01$ \\
\hline
\end{tabular}

Досегашните варианти и сценарии на числено решение показват вертикално подхранване от 16 до 58 L/s за моделната област. Работата по модела е наложително да продължи и за в бъдеще, като един от вариантите достигнал най-близки стойности между измерени и моделирани напори в подземните води изчислява вертикално подхранване от 20,7 L/s.

Численият модел не е локално прецизиран поради липсата на средна стойност на подхранване.

Площта на моделната област е $202,97 \mathrm{~km}^{2}$, което е 84,4 \% от общата площ на ПВТ или общо за тялото се получава $24,5 \mathrm{~L} / \mathrm{s}$.

\section{Метод на Döll et al. за оценка на естественото подхранване на ПВТ „Порови води в Неоген - Благоевград"}

За проверка на получените резултати от предходните решения е използван метод, предложен от Döll и др. през 2002 г. (Döll et al., 2002; Döll \& Fiedler, 2007; 2008). Този метод е използван и у нас за решаване на различни хидрогеоложки задачи (Benderev et al., 2015; Vasileva, 2016; Ivanov et al., 2017; Georgiev, 2016; Димитрова, $2017^{4}$ ). Методът се основава на три вида входни данни: наклона на релефа, вида на почвения слой и вида на скалите. Въз основа на това авторите са извели проста емпирична зависимост, която оценява величината на подземното подхранване като част от общия речен отток:

${ }^{4}$ Димитрова, К. 2017. Приложение на ГИС за определяне ролята на подземните води при формирането на повърхностостния отток в басейна на река Струма. СУ. ГГФ. 66 с. 


$$
\begin{aligned}
& R_{g}=\min \left(R_{g \max }, f_{g w} * R_{l}\right) \\
& \text { като } f_{g}=f_{s} * f_{t} * f_{a} * f_{p g}
\end{aligned}
$$

където: $R_{g}$ max - максимално възможно подхранване на подземни води в зависимост от механичния състав на почвата, $\mathrm{mm} / \mathrm{d} ; R_{l}-$ общ речен отток от съответния водосбор, $\mathrm{mm} / \mathrm{d} ; f_{g}$ - коефициент на подземното подхранване на реките (като дял от общия отток); $f_{s}$ - коефициент, свързан с наклона на склона; изменя се от 0 до 1 в зависимост от ьгъла на наклона на склона; най-висок е при хоризонтални терени, а най-нисък при стръмни склонове; $f_{t}-$ коефициент, свързан с механичния състав на почвата, също се изменя от 0 до 1 (т.е. колкото е по-песъчлива почвата, толкова е по-пропусклива и коефициентът е близък до 1); $f_{a}$ - коефициент, свързан с характера на водоносния хоризонт, отново се изменя от 0 до 1 и характеризира проницаемостта на скалите; $f_{p g}-$ коефициент, свързан с вечната замрьзналост/ледници (поради местоположението на изследвания район този коефициент не е използван).

Речният отток е изчислен по методика, използвана в НИМХ, като тук е използван регионализационният подход. Той се базира на корелативните връзки между характерните водни количества (в случая средномногогодишните водни количества към хидрометричните станции) и някоя от основните характеристики на водосборните басейни. Тези връзки се установяват след подробен анализ и обосновка.

В практиката се използват главно регресионни зависимости от типа: $Q_{\mathrm{o}}=$ $f\left(H_{\mathrm{cp}}\right)$ - връзка между оттока и средната надморска височина и $Q_{\mathrm{o}}=f(F)$ - връзка между оттока и площта на водосбора.

Въз основа на графиката, показана на фигура 6, може да се изчисли какво е средномногогодишното водно количество за разглежданата област. Получените резултати са представени на фигура 7. Разкритата част на ПВТ е 104,57 km², която площ отговаря на $111 \mathrm{~L} / \mathrm{s}$. Подземният компонент, участващ при формиране на този повърхностен отток, е 0,28. Тогава се получава средно $31 \mathrm{~L} / \mathrm{s}$ подхранване на разкритата част от ПВТ.

В таблица 3 са обобщени резултатите за естественото подхранване на ПВТ „Порови води в Неоген - Благоевград”, получени с използване на различните методи. Те показват добра сходимост, като се има предвид времевата изменчивост на подхранването.

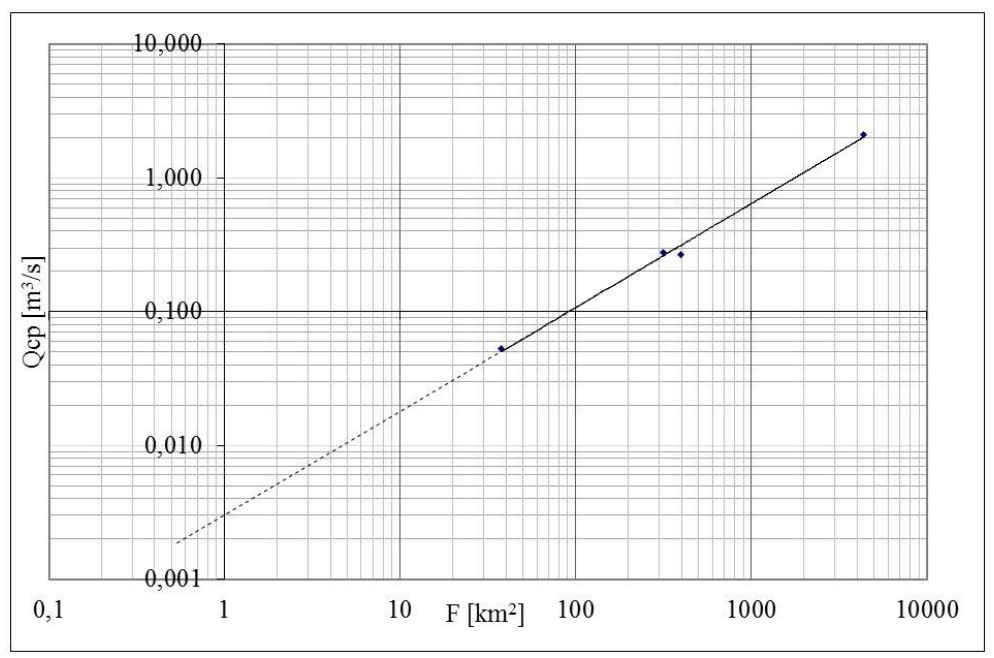

Фиг. 6. Районна зависимост на средния речен отток $Q_{\mathrm{cp}}=f(F)$ за Благоевградска котловина Fig. 6. Area dependence of the average river flow $Q_{\mathrm{cp}}=f(F)$ for the Blagoevgrad valley 


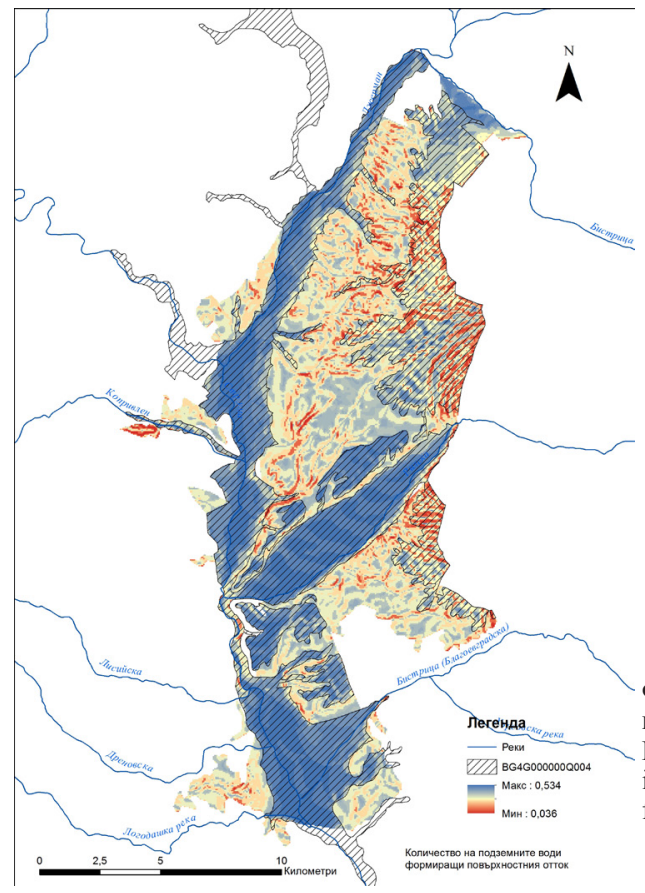

Фиг. 7. Карта, показваща ролята на подземните води във формирането на общия повърхностен отток Fig. 7. Map showing the role of groundwater in forming the total surface runoff (groundwater recharge factor)

Таблица 3. Обобщение на получените резултати за естественото подхранване на ПВТ „Порови води в Неоген - Благоевград”

Table 3. Summary of the results obtained for the natural recharge of groundwater body «Porous waters in Neogene - Blagoevgrad»

\begin{tabular}{|l|c|c|c|}
\hline \multirow{2}{*}{\multicolumn{1}{|c|}{ Използван метод }} & \multicolumn{3}{c|}{ Подхранване, L/s } \\
\cline { 2 - 4 } & 2017 & 2018 & $1981-2017$ \\
\hline Хидродинамичен геостатистически модел & & 27,3 & \\
\hline Хидродинамичен числен модел & & 24,5 & \\
\hline Емпиричен метод на Dӧ1l и др. & & & 31 \\
\hline Балансов метод Благоевград & 74,03 & & \\
\hline Балансов метод - Дупница & 140,1 & & 27 \\
\hline Инфилтрация на валежи & & & \\
\hline
\end{tabular}

\section{Заключение}

Подземното водно тяло „Порови води в Неоген - Благоевград“ е разгледано комплексно в няколко аспекта с цел определяне неговото естествено подхранване. Използвани са различни методи и подходи, като получените резултати дават съпоставими оценки.

Стойностите за естественото подхранване на изследваното ПВТ, получени по хидродинамичните модели и емпиричния метод, разработен от Döll със съавтори (Döll et al., 2002; Döll, Fiedler, 2007, 2008), дават добра сходимост. Сравнени с изчисленото подхранване от инфилтрацията на валежи за период от 37 години, те показват съпоставими величини, с особено добра сходимост c резултата от хидродинамичния геостатистически модел. Използваният комплексен подход с комбиниране на различни методи предоставя добри 
възможности за прецизна оценка на естественото подхранване на подземните води в неогенските седименти на Благоевградската котловина. Той може да бъде успешно прилаган за определяне на естествените ресурси на подземните води и за други подобни подземни водни тела. По този начин в значителна степен биха могли да се подобрят ресурсните оценки, управлението и опазването на подземните води в България.

\section{Литература \\ References}

Benderev, A., T. Orehova, S. Kolev, V. Hristov, I. Ilieva. 2015. Groundwater contribution to the river runoff in the Vitosha Nature Park (Bulgaria). Review of the Bulgarian Geological Society, vol. 76, 2-3, 109-121 (in Bulgarian, with English abstract).

Big encyclopedia Bulgaria. 2011. Vol. 1, Sofia, „Trud““, 282 p. (in Bulgarian).

Childs, C. 2004. Interpolating Surfaces in ArcGIS Spatial Analyst. ArcUser, JulySeptember 2004, 32-35. www.esri.com

Cushman, J., D. Tartakovsky. 2016. The Handbook of Groundwater Engineering. Third Edition, CRC Press. 1074 p.

Döll, P., B. Lehner, F. Kaspar. 2002. Global modeling of groundwater recharge. In: Proc. Third Int. Conf. on Water Resources and Environment Research, Technical University of Dresden, Germany, vol. I, 27-31.

Döll, P., K. Fiedler. 2007. Global-scale modeling of groundwater recharge. Hydrology and Earth System Sciences Discussions, 4(6), 4069-4124.

Döll, P., K. Fiedler. 2008. Global-scale modeling of groundwater recharge. Hydrology and Earth System Sciences Discussions, European Geosciences Union, 12 (3), 863-885.

Galabov, M., N. Stoyanov. 2005. Groundwater dynamics. Publishing house „V. Nedkov", Sofia, 202 p. (in Bulgarian).

Garnero, G., D. Godone. 2013. Comparisons between different interpolation techniques. The International Archives of the Photogrammetry, Remote Sensing and Spatial Information Sciences, Volume XL-5/W3, The Role of Geomatics in Hydrogeological Risk, 27 - 28 February 2013, Padua, Italy, 139-144.

Georgiev, B. 2016. Balance of soil resources and agricultural land in Bulgaria. Geography and Friends, Proceedings of the 60th Anniversary of Prof. Dr. Vesselin Boyadjiev and 35 years of teaching at Sofia University "St. Kliment Ohridski», Paradigma Publishing House, 57-68 (in Bulgarian).

Ivanov, M., T. Orehova, A. Toteva, M. Trayanova, A. Benderev. 2017. The role of the groundwater in the formation of river flow of the Arda river basin (Southern Bulgaria). XXVII Conf. of the Danubian Countries on Hydrological Forecasting and Hydrological Bases of Water Management: electronic book with full papers, 26-28 Sept. 2017, Golden Sands, Bulgaria. - Sofia: NIMH-BAS, 90-99.

Kresic, N., A. Mikszewski. 2012. Hydrogeological Conceptual Site Models: Data Analysis and Visualization. CRC Press., $600 \mathrm{p}$.

Vasileva, T. 2016. Spatial distribution of the groundwater recharge index in Lefedzha river basin. Engineering geology and hydrogeology, 30, 17-30 (in Bulgarian, with English abstract). 